\title{
Severe early-onset axonal neuropathy due to MFN2 deficiency
}

INSERM

\section{Source}

INSERM. (1999). Orphanet: an online rare disease and orphan drug data base. Severe early-onset axonal neuropathy due to MFN2 deficiency. ORPHA:90118

Severe early-onset axonal neuropathy due to MFN2 deficiency is a rare axonal hereditary motor and sensory neuropathy characterized by early onset ( $<10$ years) progressive distal muscle weakness and wasting of the lower limbs and later, to a lesser extent the upper limbs resulting in foot and wrist drop, areflexia, skeletal deformities (kyphoscoliosis, pes cavus with flattening, joint contractures), mild sensory impairment with vibration sense reduced to a greater extent than pain, optic atrophy and hearing loss. Wheelchair dependence by adolescence is usual and respiratory impairment with diaphragmatic paralysis may develop. 